\title{
ANÁLISE DO DESGASTE ABRASIVO NA SUPERFÍCIE DE ROLETES DE CARGA DE TRANSPORTADORES DE CORREIA*
}

\author{
Zirlene Alves da Silva Santos ${ }^{1}$ \\ Maxsuell Mendes Gonçalves ${ }^{2}$ \\ Victor Pires Alves do Carmo ${ }^{3}$
}

\section{Resumo}

O desgaste abrasivo é o principal responsável por quebras de equipamentos e, como consequência, paradas não programadas para manutenção; pois causa a perda progressiva de material das partes móveis em contato e movimento relativo. O presente estudo analisa 0 desgaste abrasivo na superfície do rolete de carga dos transportadores de correia. Para a análise foi utilizado o equipamento abrasômetro do tipo roda de borracha conforme norma ASTM G65. Os procedimentos de ensaio contemplaram: o corte de quatro corpos de prova de aço 1020, limpeza, pesagem - utilizando balança de precisão, avaliação superficial com rugosímetro e ensaio de dureza. Dois corpos de prova foram revestidos com a tinta Laranja Munsell 2,5YR6/14m, para simular as condições de campo. Em seguida, foi realizado ensaio no abrasômetro ASTM G65; utilizando o procedimento "A" previsto na norma ASTM G65 classificado como desgaste severo com carga de $130 \mathrm{~N}$. Logo depois, foi calculado o volume de material perdido e a taxa de desgaste. Os resultados obtidos nos ensaios possibilitaram concluir que, o desgaste predominante na superfície dos roletes de carga é o abrasivo por 3 corpos, em função, principalmente, do transbordo de minério do processo. A superfície do corpo de prova, sem revestimento, apresentou uma perda de material que compromete a vida útil do rolete e da correia. Já, na amostra revestida, foi possível observar que o desgaste abrasivo por três corpos ocorre, mas é reduzido consideravelmente; isso pode ser explicado pela diminuição da rugosidade superficial.

Palavras-chave: Desgaste abrasivo, Roletes de carga, Manutenção, Transportador de correia.

\section{ANALYSIS OF ABRASIVE WEAR ON THE SURFACE OF PIPE ROLLERS OF BELT CONVEYORS}

\section{Abstract}

Abrasive wear it is the main responsible for equipment breaks and, as a consequence, unscheduled maintenance stops; As it causes the progressive loss of material from moving parts in contact and relative movement. The present study analyzes the abrasive wear on the surface of the load roller of the conveyors belt. For the analysis, the rubber wheel type abrasometer was used according to ASTM G65. The test procedures included: the cutting of four 1020 steel specimens, cleaning, weighing - using precision balance, surface evaluation with a rugosimeter and hardness test. Two specimens were coated with Munsell Orange ink 2.5YR6 / 14m to simulate field conditions. Then, the ASTM G65 abrasion test was performed; Using procedure "A" provided for in ASTM G65 - classified as severe wear with 130N load. Next, the volume of material lost and the rate of wear were calculated. The results obtained in the tests made it possible to conclude that the predominant wear on the surface of the load rollers is the abrasive by 3 bodies, mainly due to the ore transhipment of the process. The surface of the test piece, uncoated, has a loss that compromises the life of the roller and the belt. Already, in the coated sample, it was possible to observe that the abrasive wear by three bodies occurs, but is reduced considerably; This can be explained by the decrease in surface roughness.

Keywords: Abrasive Wear, Load roller; Maintenance, Conveyor Belt.

\footnotetext{
${ }^{1}$ Doutorado em engenharia de materiais, professor Adjunto III, Departamento de Controle e Automação, Universidade Federal De Ouro Preto, Ouro Preto, MG, Brasil.

2Engenheiro mecânico, Graduado, DECAT, Universidade Federal de Ouro Preto, Ouro Preto, MG, Brasil.

${ }^{3}$ Engenharia mecânica, Graduando, DECAT, Universidade Federal de Ouro Preto, Ouro Preto, MG, Brasil.
} 


\section{INTRODUÇÃO}

As mineradoras desempenham um importante papel dentro do contexto econômico mundial por fornecerem matéria prima para diversos tipos de indústrias. É a partir do minério que é possível produzir componentes e equipamentos que são utilizados no nosso dia a dia.

O instituto brasileiro de mineração IBRAM [1] demonstrou o potencial minerador brasileiro e afirmou que, o Brasil possui cerca de 72 tipos de substâncias minerais das quais 23 são metálicas, 45 não metálicas e 4 energéticas. São 1.820 lavras garimpeiras; 830 complexos de água mineral; e 13.250 licenciamentos. O Índice da Produção Mineral (IPM) do país, que mede a variação na quantidade produzida, apresentou uma retração de 3,7\% no primeiro semestre de 2016 quando comparado a igual período do ano anterior. Os principais fatores determinantes da redução na produção mineral foram a demanda e os preços internacionais de commodities minerais. De forma complementar, fatores operacionais e climáticos também exerceram influência, como o excesso de chuvas, paradas para manutenção de equipamentos, alterações de fluxos de trabalho, reparos em barragens de rejeitos, menores teores do minériolrecuperação nas usinas, atrasos na conclusão dos serviços de infraestrutura, disponibilidade de equipamentos, dentre outros DNPM [2].

Um dos principais elementos de competitividade da indústria de mineração é a eficiência operacional. Para tanto, a disponibilidade física do equipamento representa o principal indicador de qualidade da área de manutenção. Uma forma de garantir a disponibilidade física é por meio de eficientes sistemas de gestão de manutenção.

De acordo com Kardec e Nascif [3], a manutenção pode ser compreendida como a garantia da disponibilidade das funções dos equipamentos e das instalações; que possibilitem o atendimento de um processo de produção e, por conseguinte, de preservação do meio ambiente com confiabilidade, segurança e custo adequados.

Reflexões quanto aos custos diretos e indiretos estão presentes na rotina dos técnicos e engenheiros nas indústrias de mineração. As áreas de manutenção das indústrias relacionadas vêm combatendo o desgaste, visando aumentar o tempo médio entre falhas, reduzir as paradas não programadas e otimizar a troca de componentes. O objetivo é reduzir os custos diretos de regeneração e reposição de componentes e custos indiretos de parada de produção, manutenção e estoque, Suzuki [4].

Assim, esta pesquisa analisa e quantifica o desgaste abrasivo na superfície de roletes de carga de transportadores de correia. É utilizada uma abordagem qualitativa com metodologia exploratória, descritiva, bibliográfica e experimental.

Ainda segundo Suzuki [4] em setores minero metalúrgicos, onde o desgaste causa a parada ou a diminuição da produção ou envolve elevados custos de manutenção, não é suficiente adquirir conhecimentos apenas em materiais e processos metalúrgicos e/ou mecânicos de fabricação. É necessário atentar para o tribossistema; pois fenômenos como atrito e desgaste afetam o desempenho de equipamentos e componentes. 


\subsection{Fenômenos Tribológicos}

O termo Tribologia foi abordado pela primeira vez em um relatório do comitê governamental Inglês de educação e ciência, em 1966; nesse relatório, o termo foi definido como "... The science and technology of interacting surfaces in relative motion and the practices related thereto" em tradução livre como: "A ciência e tecnologia de superfícies interativas em movimento relativo e dos assuntos e práticas relacionadas", Jost [5].

A análise de sistemas tribológicos está caracterizada pela norma DIN 50320 Zum Gahr [6]. A estrutura de um sistema tribológico é mostrada na Figura 1 consistindo usualmente de quatro elementos: Corpo sólido; Contra-corpo; Elemento de interface; E meio ambiente.

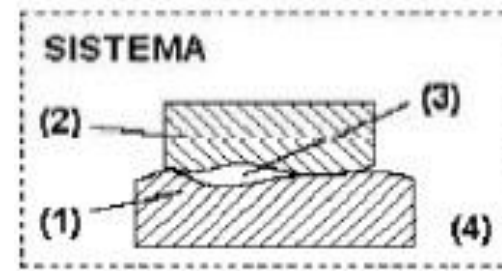
(1) Corpo
(2) Contra-corpo
(3) Interface
(4) Meio

Figura 1: Sistema tribológico Fonte: Zhum Ghar [6]

Hutchings [7], afirma que quando existe atrito e movimento relativo entre dois materiais ocorre uma perda progressiva de material. Assim, o desgaste pode ser caracterizado como o prejuízo mecânico de uma das partes ou ambas.

\subsection{Desgaste abrasivo}

Dentre os diversos tipos de desgaste, o desgaste abrasivo é o principal responsável por quebras de equipamentos, paradas não programadas e reposição de peças; pois causa a perda progressiva de material das partes móveis em contato e movimento relativo. Além do desgaste abrasivo, outros fenômenos como o desgaste erosivo, por deslizamento e por fadiga também são frequentemente observados, Dallmann [10].

Segundo Eyre [8], o desgaste abrasivo é responsável por $50 \%$ das causas de falhas das máquinas ou componentes. De todos os diferentes tipos de desgaste, portanto, o desgaste abrasivo é o que ocorre em mais de $50 \%$ dos casos, sendo considerado como o mais severo e o mais comumente encontrado na indústria.

Budisnski [9], descreveu a classificação de desgaste abrasivo; o autor afirmou que é classificado como desgaste abrasivo: "aquele que é produzido por partículas duras que se movem em uma superfície sólida". Nesses casos, a partícula que produz o desgaste sobre a superfície deve ser mais dura, danificando assim a superfície mais macia e promovendo perda gradativa de material quando há movimento relativo. Essas partículas duras possuem um certo grau de cantos agudos que promovem o corte por uma ação cisalhante na superfície. Existem dois tipos característicos de desgaste abrasivo: desgaste por dois corpos e desgaste por três corpos.

No desgaste por dois corpos, as partículas se movem livremente sobre uma superfície. Já no desgaste por três corpos as partículas abrasivas, que podem ser em função de contaminantes como: poeira, minério entre outros, ocorrem na interface 
entre o corpo sólido e o contra corpo. "O desgaste quando envolve três corpos é cerca de duas a três vezes menor do que quando envolve dois corpos; pois, no caso de três corpos, devido à variação no ângulo de ataque apenas uma pequena porção das partículas causam desgaste" Pascoali [10].

Zum-Gahr [6], definiu uma classificação em relação ao tipo de dano que a superfície sofre:

1 -Microsulcamento: O microsulcamento é uma deformação plástica da superfície sem perda de material que forma um sulco com o acúmulo de material deformado nas partes laterais e frontais local.

2 - Microcorte: Formação de micro cavacos com pequena deformação plástica

3 - Trincamento: É um tipo de dano que se restringe a materiais frágeis, ocorre quando as tensões impostas pelo sistema tribológico superam as tensões críticas para formação de trincas. Caracterizado pela formação de grandes partículas de abrasão.

Uma característica deste tipo de desgaste é a superfície com ranhuras, tipo arada. Um corpo duro e com ponta aguda age arando a superfície formando canais profundos e, nesse caso, a tensão ou forças que atuam no sistema são baixas o suficiente para não causar a quebra deste corpo duro; muito comum em mancais de deslizamento e equipamentos mineradores e agrícolas, Hutchings [7].

\subsection{Transportadores de correia}

Segundo a empresa fornecedora de correias para transportadores ssruber, a ideia básica de funcionamento desse equipamento consiste em duas ou mais polias que movimentam uma superfície em que determinados materiais ou objetos são transportados; é um equipamento estratégico dentro do sistema produtivo minerometalúrgico; é usado também em diversos segmentos.

Sacramento [12] descreve os principais componentes da correia transportadora são:1 - Correia; 2 - Tambores; 3- Guias laterais; 4 -Roletes; 5 -Freios; 6 - Chute; 7 - Estrutura; 8 - Drive. O Drive é o conjunto de acionamento do sistema composto por um motor elétrico e um sistema de transmissão redutor de velocidade; geralmente as correias tem uma baixa velocidade. $\mathrm{E}$, em alguns casos, possui um inversor de frequência a fim de minimizar os solavancos na partida do motor.

No conjunto do sistema transportador de correia é importante destacar que os roletes de carga são componentes indispensáveis para o desempenho do transportador de correia. Nesse sentido, os roletes estão expostos a fenômenos tribológicos; pois o material transportado já é um gerador de atrito e desgaste. Nesse sentido, a falta de inspeção e manutenção poderá se traduzir em atrito e desgaste abrasivo. $\mathrm{O}$ desgaste abrasivo pode abreviar a vida útil de componentes e do próprio equipamento e componentes.

\subsubsection{Rolete de carga}

Localizados no lado superior dos transportador, a função do rolete de carga é suportar a correia carregada nas áreas fora das zonas de descarga (chutes). São encontrados em variadas disposições, desde planos com um rolo até em disposição catenária que podem possuir vários rolos combinados.

Formando um conjunto robusto e extremamente eficaz. Os tubos são em aço carbono com costura e espessura mínima de $3,75 \mathrm{~mm}$, com eixo em aço SAE 1020 
trefilados e retificados no alojamento do anel interno do rolamento com tolerância h6. O alojamento do rolamento é composto de caixa estampada em aço SAE 1020 calibrado com tolerância M7 e abas posteriormente usinadas.

O conjunto de vedação é do tipo permanente composto de anel de encosto, rolamento rígido de esferas com folga $\mathrm{C} 3$, labirinto duplo radial, arruela lisa com anel elástico, anel defletor, retentor de borracha nitrílica e tampa de fechamento em chapa de aço estampada. Em todos os componentes é aplicada a graxa especial a base de lítio, formando assim um conjunto de lubrificação permanente.

A vida útil de um rolo é estabelecida segundo a norma ABNT - NBR 6678. A vida de um rolete de carga depende de muitos fatores tais como, material transportado espessura da parede do tubo, eficiência da vedação do rolamento, meio ambiente, etc. Porém, como todos estes fatores não são quantificáveis, a vida do rolamento é utilizada como indicativo da vida do rolo. Entende-se como vida do rolamento, 0 número de horas a uma determinada rotação que $90 \%$ dos rolamentos atinge, antes que apareçam os primeiros sinais de fadiga (descascamento) em seus anéis ou corpos rolantes.

A vida real da superfície do rolete de carga pode ser, portanto, inferior à vida do rolamento. É recomendado normalmente uma vida de 30.000 horas a $500 \mathrm{rpm}$, sendo este o valor de referência. Para aplicações especiais, a vida do rolamento deve ser acordada entre usuário e fornecedor.

A figura 2 ilustra a configuração dos roletes de carga dentro do sistema do transportador de correias em que os roletes de carga são submetidos.

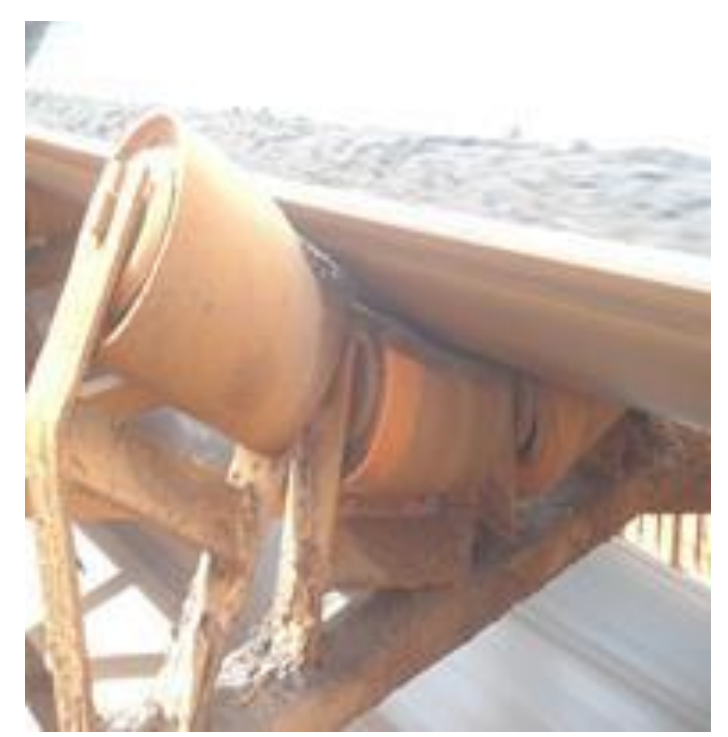

Figura 2: Configuração dos roletes de carga dentro do sistema do transportador de correias Fonte: Alvarenga [13]

Conforme ilustra a figura 2, o desgaste abrasivo é muito comum em casos onde há transbordo de material, contaminando e travando os roletes de carga. Os roletes de carga não devem, em hipótese alguma, trabalhar com seus rolamentos travados. Em caso de desgaste superficial ou contaminação do rolamento, o rolete de carga deve imediatamente ser substituído, caso contrário é grande o risco de danos na correia. A perda de material pode ser muito intensa, chegando ao eixo de rolamento dos roletes de carga. 
A classificação para este tipo de desgaste é desgaste severo a três corpos. Este ocorre quando as partículas duras são livres para rolar e deslizar entre as duas superfícies. No desgaste abrasivo de três corpos, as partículas abrasivas soltas passam $90 \%$ do tempo rolando, e apenas $10 \%$ do tempo em contato com a superfície, Zum Gahr [6].

\section{MATERIAIS E MÉTODOS}

A metodologia empregada na pesquisa é qualitativa com abordagem exploratória, descritiva, bibliográfica e experimental. Para realizar a simulação do desgaste abrasivo, na superfície dos roletes de carga, foram cortadas 4 amostras de aço SAE1020; pois este aço é utilizado para a confecção da superfície do rolete de carga. Porém, duas amostras foram revestidas com a tinta Laranja Munsell 2,5YR6/14, mais conhecida como laranja segurança; utilizada para revestir os roletes de carga que são empregados no transportador de correia. O revestimento foi necessário, portanto, para possibilitar que a amostra estivesse nas mesmas condições do rolete no sistema do transportador de correia.

Foram utilizados também máquina para leitura de medida de dureza vickers, medidor de temperatura infravermelho, sensor de rugosidade (rugosímetro) e balança de precisão 0,001g. O Material abrasivo utilizado foi areia de alto teor de sílica e com granulometria das peneiras 50/70 AFS.

A norma ASTM G-65 propõe um equipamento para ensaios de desgaste abrasivo, onde a amostra é disposta num plano vertical e forçada horizontalmente contra um disco de borracha que gira a uma rotação constante de $200 \mathrm{RPM} \pm 10$, ao mesmo tempo em que um abrasivo é jateado entre as superfícies da amostra e do disco de borracha, causando assim o desgaste do corpo de prova. figura 3 :

Os procedimentos metodológicos utilizados no ensaio estão representados na

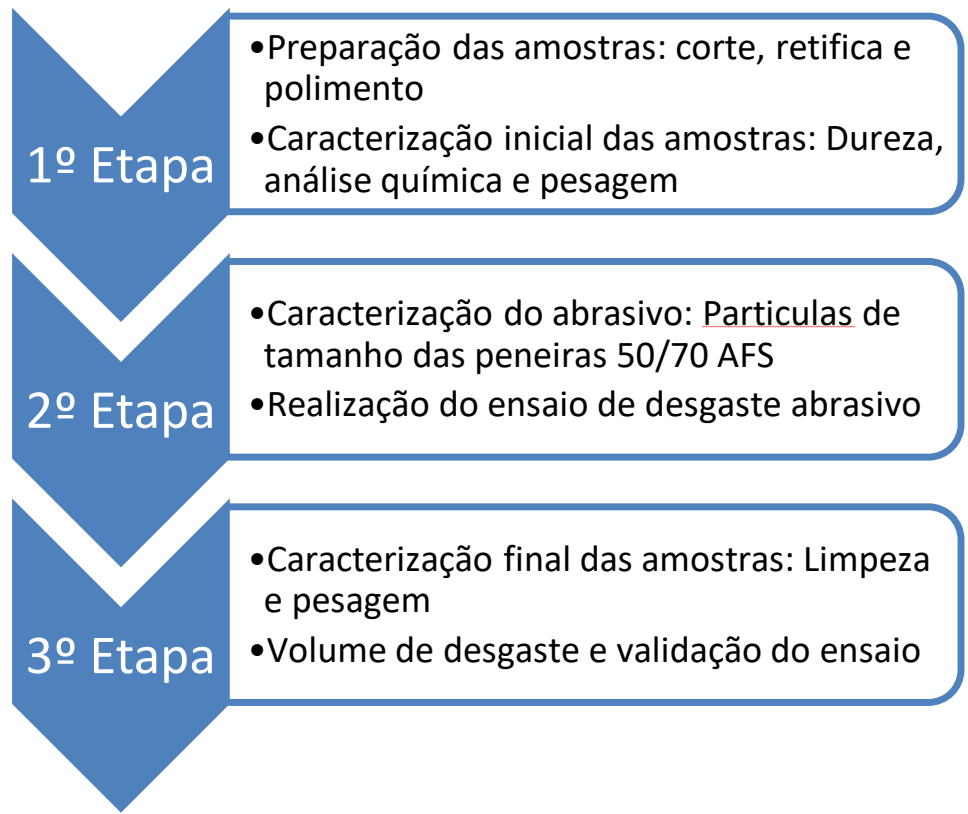

Figura 3: Fluxograma de procedimentos utilizados na pesquisa Fonte: Pesquisa direta (2017) 
A figura 3 apresenta as etapas seguidas para realização do ensaio. Na primeira etapa a amostra é cortada nas dimensões $25 \times 76 \times 6,2 \mathrm{~mm}$ seguido de retifica e polimento para chegar na rugosidade desejada que, segundo a norma ASTM G65, deve ser abaixo de $0,8 \mu \mathrm{m}$. Após o polimento foram feitas 3 medidas de leitura de dureza vickers HV0,5 para cada amostra do aço SAE 1020; sendo utilizado a média aritmética simples das 3 leituras de dureza realizadas; em seguida foi realizada a pesagem em uma balança de precisão $0,001 \mathrm{~g}$.

$\mathrm{Na}$ segunda etapa realiza-se a preparação do abrasivo - que é uma areia com alto teor de sílica em torno de $90 \%$. O abrasivo é peneirado nas peneiras 50/70 AFS. Após a caracterização do abrasivo as amostras são limpadas, todo vestígio de oxidação ou sujeira foram removidos antes do ensaio. As amostras, em seguida, são submetidas ao ensaio sendo pressionadas contra a roda de aço com bordas de borracha sobre uma força de $130 \mathrm{~N}$ e uma vazão do abrasivo em torno de $360 \mathrm{~g} / \mathrm{min}$.

A terceira etapa é a retirada da amostra do equipamento, limpeza com álcool para retirar pequenas partículas de areia presas a superfície do aço e pesagem. Após a obtenção do peso, pós ensaio, é feita uma subtração das massas inicial e final, e o valor obtido é usado na (equação 1), de densidade, para calcular o volume perdido.

$$
\mathrm{V}=\frac{M}{D} \times 1000
$$

$\mathrm{V}=$ volume perdido $\left(\mathrm{mm}^{3}\right)$.

$M=$ massa perdida $(\mathrm{g})$.

$\mathrm{D}=$ Densidade $\left(\mathrm{g} / \mathrm{cm}^{3}\right)$.

Normalmente ocorre desgaste da borracha que recobre o disco. Assim, o diâmetro externo da roda deve ser medido antes e depois de cada ensaio, para que 0 volume perdido calculado na equação 1 possa ser corrigido. Para essa correção utiliza-se a (equação 2):

$$
\mathrm{V}=\frac{228,6(\mathrm{~mm})}{d} \times \text { volume perdido calculado }\left(\mathrm{mm}^{3}\right)
$$

$\mathrm{V}=$ volume perdido ajustado $\left(\mathrm{mm}^{3}\right)$

$\mathrm{d}=$ Diâmetro da roda após o ensaio

Após o cálculo do volume perdido, o valor é utilizado na (equação 3) de Archard para obter o coeficiente de desgaste do aço.

$$
\mathrm{Q}=\mathrm{K} \frac{W}{H} \times \mathrm{S}
$$

$\mathrm{Q}=$ Taxa de desgaste $\left(\mathrm{mm}^{3}\right)$

$\mathrm{K}=$ Coeficiente de desgaste (adimensional)

$\mathrm{W}=$ Força (Newtons)

$\mathrm{H}=$ Dureza do material desgastado (Vickers)

$\mathrm{S}$ = Distância de deslizamento (4.309 metros) 6000 ciclos

Analisando os resultados e comparando com os valores mencionados na norma ASTM G65, é possível validar o ensaio.

Após obter com precisão os dados pertinentes as características do rolete de carga, foram preparados corpos de prova utilizando o mesmo material da superfície dos roletes de carga, para estudar o desgaste que acomete a superfície do rolete de carga. A figura 4 mostra os corpos de prova. 


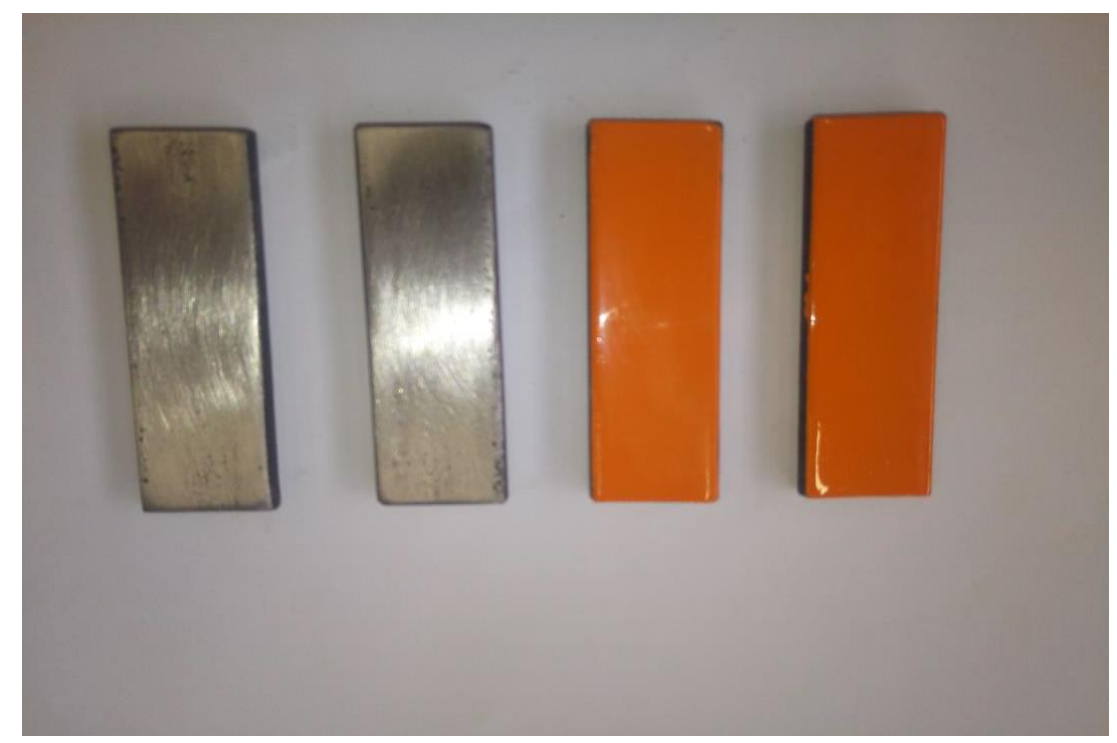

Figura 4: Corpos de prova preparados para ensaio Fonte: pesquisa direta (2017)

Conforme mostra a figura 4, dois corpos de prova estão sem revestimento. Isso foi necessário para analisar o efeito da abrasão na superfície revestida e não revestida. As amostras com revestimento foram preparadas com a mesma rugosidade das amostras sem revestimento. A rugosidade foi medida com a utilização de um rugosímetro digital. Foram feitas 3 leituras de rugosidade do corpo de prova e utilizada a média aritmética simples das leituras. Porém, ao fazer a leitura novamente nas amostras com revestimento, foi notado que a rugosidade diminuiu drasticamente chegando a valores inferiores a $0,1 \mu \mathrm{m}$. Fazendo a leitura da pesagem, foi observado que as amostras que tinham revestimento apresentaram massas um pouco superior as amostras que não tem revestimento.

Dentre vários procedimentos de ensaio padronizados pela norma ASTM G65 foi escolhido o procedimento "A". Este procedimento é um ensaio relativamente severo que contempla materiais de baixa a extrema resistência abrasiva. $O$ abrasivo foi criteriosamente selecionado pelas peneiras 50 AFS que tem a malha de $300 \mu \mathrm{m}$ e a peneira de 70 AFS; que tem a malha de abertura de $212 \mu \mathrm{m}$. Logo, o tamanho médio das partículas fica em torno de 125-150 $\mu \mathrm{m}$. O tempo de ensaio de 6000 ciclos para uma roda que gira a $200 \mathrm{rpm}$ equivale a 30 minutos. Durante o ensaio, como a rotação da roda da máquina utilizada é de 210 rpm para 6000 ciclos, o tempo é reduzido para 28,6 minutos.

É importante ressaltar que, o controle da temperatura é extremamente importante durante o ensaio, pois uma vez que ela esteja bastante elevada, a borracha sofre incrustação de partículas abrasivas e consequentemente pode gerar desgaste adesivo. 


\section{RESULTADOS E DISCUSSÃO}

Após esses procedimentos iniciais de ensaio as 4 amostras foram submetidas ao ensaio. Durante o ensaio foi feito um intervalo de três em três minutos para que a borracha e o corpo de prova pudessem resfriar. A leitura da temperatura do corpo de prova durante o ensaio foi feita utilizando um termômetro infravermelho.

As tabelas 1 e 2 mostram os respectivos resultados para cada amostra. $O$ resultado do coeficiente de desgaste foi utilizado para cálculo na equação de Archard

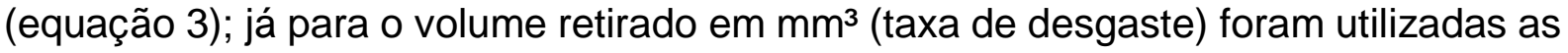
equações 1 e 2 para ajuste.

Tabela 1. Resultados para amostra 1

\begin{tabular}{|c|c|}
\hline \multicolumn{2}{|c|}{ Amostra 1 sem revestimento } \\
\hline Massa Inicial & $93,2560 \mathrm{~g}$ \\
\hline Massa Final & $91,9283 \mathrm{~g}$ \\
\hline Diâmetro da roda após ensaio & $228,3 \mathrm{~mm}$ \\
\hline Dureza Vickers & $147 \mathrm{HV} 0,5$ \\
\hline Taxa de desgaste ajustada & $169,14 \mathrm{~mm}^{3}$ \\
\hline Coeficiente de desgaste $\mathrm{K}$ & 0,044 \\
\hline Temperatura Máxima de ensaio & $78^{\circ} \mathrm{C}$ \\
\hline Rugosidade & $0,645 \mu \mathrm{m}$ \\
\hline
\end{tabular}

Tabela 2. Resultados para amostra 2

\begin{tabular}{|c|c|}
\hline \multicolumn{2}{|c|}{ Amostra 2 sem revestimento } \\
\hline Massa Inicial & $93,3554 \mathrm{~g}$ \\
\hline Massa Final & $92,0543 \mathrm{~g}$ \\
\hline Diâmetro da roda após ensaio & $228,2 \mathrm{~mm}$ \\
\hline Dureza Vickers & $146 \mathrm{HV} 0,5$ \\
\hline Taxa de desgaste ajustada & $165,90 \mathrm{~mm}^{3}$ \\
\hline Coeficiente de desgaste $\mathrm{K}$ & 0,0432 \\
\hline Temperatura Máxima de ensaio & $79,2^{\circ} \mathrm{C}$ \\
\hline Rugosidade & $0,625 \mu \mathrm{m}$ \\
\hline
\end{tabular}

É possível observar nas tabelas 1 e 2 que a perda média de material foi de $167,52 \pm 1,62 \mathrm{~mm}^{3}$ para as amostras 1 e 2 (sem revestimento) com um coeficiente de variação de $0,96 \%$. Resultado satisfatório e dentro da faixa limite da norma ASTM G65. As tabelas 3 e 4 são dados amostrais referentes as amostras 3 e 4 (com revestimento). 
Tabela 3. Resultados para amostra 3

\begin{tabular}{|c|c|}
\hline \multicolumn{2}{|c|}{ Amostra 3 com revestimento } \\
\hline Massa Inicial & $94,2224 \mathrm{~g}$ \\
\hline Massa Final & $93,4203 \mathrm{~g}$ \\
\hline Diâmetro da roda após ensaio & $228,0 \mathrm{~mm}$ \\
\hline Dureza Vickers & $142 \mathrm{HV} 0,5$ \\
\hline Taxa de desgaste ajustada & $102,30 \mathrm{~mm}^{3}$ \\
\hline Coeficiente de desgaste K & 0,0257 \\
\hline Temperatura Máxima de ensaio & $78,1^{\circ} \mathrm{C}$ \\
\hline Rugosidade & $0,114 \mu \mathrm{m}$ \\
\hline
\end{tabular}

Tabela 4. Resultados para amostra 4

\begin{tabular}{|c|c|}
\hline \multicolumn{2}{|c|}{ Amostra 4 com revestimento } \\
\hline Massa Inicial & $94,0736 \mathrm{~g}$ \\
\hline Massa Final & $93,2600 \mathrm{~g}$ \\
\hline Diâmetro da roda após ensaio & $228,0 \mathrm{~mm}$ \\
\hline Dureza Vickers & $145 \mathrm{HV} 0,5$ \\
\hline Taxa de desgaste ajustada & $109,9 \mathrm{~mm}^{3}$ \\
\hline Coeficiente de desgaste K & 0,027 \\
\hline Temperatura Máxima de ensaio & $77,2^{\circ} \mathrm{C}$ \\
\hline Rugosidade & $0,120 \mu \mathrm{m}$ \\
\hline
\end{tabular}

É possível observar nas tabelas 3 e 4 que a perda média de material foi de $103,1 \pm 0,8 \mathrm{~mm}^{3}$ para as amostras 3 e 4 com um coeficiente de variação de $0,77 \%$. Resultado também satisfatório e dentro da faixa limite da norma ASTM G65. Após os resultados obtidos a figura 5 mostra um comparativo entre as amostras sem revestimento e com revestimento em relação a taxa de desgaste:

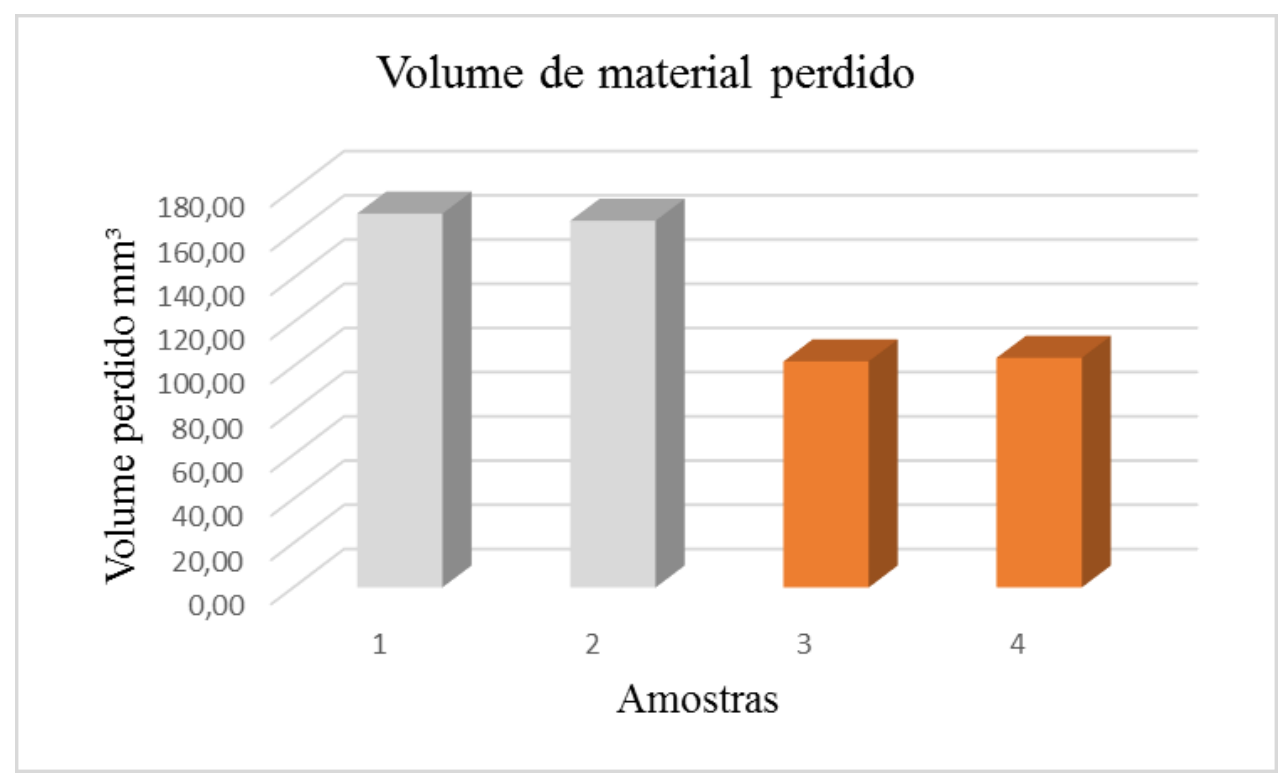

Figura 5: Indicador comparativo de volume perdido das amostras ensaiadas Fonte: Pesquisa direta (2017)

Observa-se na figura 5 que as amostras 3 e 4, que possuem o revestimento, sofreram bem menos desgaste que as amostras 1 e 2 . Nesse caso, comprova-se que a rugosidade influencia sistematicamente a taxa de desgaste, ou seja, o aumento da rugosidade causa o aumento do desgaste nas operações minero-metalúrgicas. Nas 
tabelas 1,2,3 e 4 é possível observar que o coeficiente de desgaste também diminuiu quase pela metade nas amostras 3 e 4 em relação as amostras 1 e 2.

\section{CONCLUSÃO}

Foi possível concluir, através do ensaio no abrasômetro - padrão ASTM G65, que o perfil de desgaste abrasivo na maioria das amostras nas superfícies de roletes de cargas, pode ser atenuado pelo revestimento. Entretanto, o transbordo de minério, de forma contínua, causa o desgaste do tipo três corpos, mesmo com o revestimento, mas o coeficiente de desgaste diminui expressivamente; isso pode ser explicado pela redução da rugosidade superficial.

Com a configuração do equipamento utilizada, não é possível medir a força de atrito durante o ensaio, o que dificulta também calcular a energia dissipada no processo. Analisando as amostras ensaiadas, as taxas de desgaste ficaram bem próximas com um coeficiente de variação bem baixo. Logo, os resultados são satisfatórios e o equipamento apresentou uma confiabilidade de 95\%.

\section{Agradecimentos}

A Samarco Mineração por disponibilizar as amostras para a pesquisa e possibilitar a pesquisa de campo.

\section{REFERÊNCIAS}

1. Instituto Brasileiro de Mineração. [página da internet]. IBRAM, 2016 [Acesso em 12 mai. 2017]. Dísponível em: http://www.ibram.org.br

2. Departamento Nacional de Pesquisa Mineral. [página da internet]. DNPM, 2016 [acesso em 12 mar. 2017] Dísponível em:

http://www.dnpm.gov.br/dnpm/informes/informe mineral 22016

3. Kardec, Alan; Nascif, Júlio. Manutenção: função estratégica. 3. ed. Rio de Janeiro: Qualitymark, Petrobras, 2009.

4. Suzuki, R. S. Projeto e construção de um equipamento de ensaio de desgaste micro-abrasivo por esfera rotativa livre. São Bernardo Do Campo, SP. 2013. Projeto de pesquisa. Centro universitário da FEI, 2013.

5. Jost, H. P., 1990, "Tribology-origin and future", Wear, v.136, pp.1-17.

6. Zum-Gahr, K-H., 1987, "Microstructure and Wear of Materials", Tribology Series, 10, Elsevier, pp. 1-6,

7. Hutchings, I. M. Tribology Friction and Wear of Engineering Materials. 1 $^{\circ}$ Edição,Londres, 1992.

8. Eyre, T. S. Friction and wear mechanisms of metals, In: II Seminário Sobre Materiais Resistentes ao Desgaste, Uberlândia, ABM 1991, Anais, p.263-292.

9. Budinski.K. G. Surface Engineering for Wear Resistance. Prentice Hall, Englewood Cliffs, New Jersey, 1988.

10. Pascoali. S. Introdução ao Desgaste Abrasivo. Florianópolis, SC, 2004.

11. Dallmann.J. Projeto, Construção e Validação De Um Abrasômetro Roda De Borracha. [dissertação de mestrado]. UDESC, Joinville, SC, 2012.

12. Sacramento, R. C. F. Transportadores Contínuos para Granéis Sólidos. Capítulos 5 e 7. UFBA, 2004. 
13. Alvarenga, L. C; Desgaste abrasivo: o caso de desgaste de um transportador de correia de uma empresa mineradora. [trabalho de conclusão de curso]. UFOP Ouro Preto, 2014. 